\title{
BIBECHANA
}

A Multidisciplinary Journal of Science, Technology and Mathematics

ISSN 2091-0762 (online)

Journal homepage: http://nepjol.info/index.php/BIBECHANA

\section{Study of lattice dynamics of silicon}

\author{
S. R. B. Thapa \\ Birendra Multiple Campus, Bharatpur,Chitwan, Nepal \\ Article history: Received 25 November, 2011; Accepted 14 July, 2012
}

\begin{abstract}
Lattice dynamics of Si has been investigated by using a Urey-Bradley Valence Force Field (UVFF) model which is a phenomenological model. In this model following interactions are taken into account: (i) the central force due to bond-stretching (ii) the angular force due to bond bending (iii) central force between non-bonded atoms (iv) the force due to interaction of one internal co-ordinate to adjacent internal coordinate. Calculated results of phonon dispersion curves, Debye Characteristic temperature, microscopic elastic constants and Bulk modulus of $\mathrm{Si}$ are compared with experimental results giving fairly good agreement.
\end{abstract}

Keywords: Phenomenological model; Phonon frequencies; Debye Characteristic temperature; microscopic elastic constants; Urey Bradley Valence Force Field (UVFF) approximations

\section{Introduction}

Yin and Cohen [1] investigated theoretically lattice dynamical properties of diamond crystal Si using ab initio pseudopotential theory within the local density functional formalism. Inter-planar and inter-atomic force constants in Si has been investigated using adiabatic bond-charge model by Fleszar and Resta [2].

Bose et al.[3] investigated phonon dispersion curves of $\mathrm{Si}$ in three symmetry directions of Brillouin zone using the angular forces of type employed by deLaunay and Clark, Gazis and Wallis. Phonon frequencies, elastic constants, specific heat and Debye temperature of diamond structure crystal $\mathrm{Si}$ has been investigated by Zdetsis and Wang [4] using Born Von-Karman (BVK) model. Lattice dynamical calculations of phonon scattering at ideal Si-Ge interfaces has been done by Zhao and Freund [5].

Dispersive elastic constants of Si has been determined by Jakata and Every [6].Maranganti and Sharma [7] incorporated third and fourth order spatial derivatives of the displacement field in the elastic wave equation to calculate elastic constants of Si.

Urey-Bradley Valence Force Field (UVVF) model which is successfully used to investigate the lattice dynamics of diamond by Thapa [8] is extended to study the lattice dynamics of diamond like crystals Si. In this paper Urey-Bradley Valence Force Field (UVVF) is assumed to describe the forces operating inside the solids which crystallize in diamond structure. Urey-Bradley Valence Force Field is the combination of the simple valence force field and the central interaction between the non-bonded atoms. Thus forces considered are those which resist the extension or compression of valence bonds together with those which oppose the bending or torsion of bonds and central interaction between the non-bonded atoms. Contribution to potential energy from other neighbours except first and second neighbours has been neglected because of the short range character of the force field. The Coulomb electrostatic interactions are not considered since atomic charges are either zero or very small. 


\section{Theoretical Models}

Theoretical model used in this paper is reported by Thapa [8].The secular determinant for the normal modes of vibration of the atoms in the crystal is given by

$$
\left|D_{\alpha \beta}\left(\mathbf{q}, k k^{\prime}\right)-\omega^{2} \delta_{\alpha \beta} \delta_{k k^{\prime}}\right|=0
$$

$\mathrm{D}_{\alpha \beta}(\mathbf{q}, \mathrm{kk})$ represents the elements of the dynamical matrix $\mathrm{D}(\mathbf{q})$ and $\omega$ is the angular frequency of the normal modes of the vibration of the crystal. $\delta_{\alpha \beta}$ and $\delta_{\mathrm{kk}^{\prime}}$ are the usual kronecker delta functions.

Solving the secular determinant for long wavelength limit, following expressions for the three elastic constants for the diamond structure crystal are obtained in terms of model parameters $\mathrm{k}_{\mathrm{r}}, \mathrm{k}_{\mathrm{rr}}, \mathrm{k}_{\mathrm{r} 1}$ and $\mathrm{r} / \mathrm{r}_{0}{ }^{2}$.

$$
\begin{gathered}
\mathrm{C}_{11}=1 / 2 \mathrm{a}\left[(1 / 3) \mathrm{k}_{\mathrm{r}}-(1 / 6) \mathrm{k}_{\mathrm{rr}}+4 \mathrm{k}_{\mathrm{rl}}+4\left(\mathrm{\Upsilon} / \mathrm{r}_{0}^{2}\right)\right] \\
\mathrm{C}_{12}=1 / 2 \mathrm{a}\left[(1 / 3) \mathrm{k}_{\mathrm{r}}-(1 / 6) \mathrm{k}_{\mathrm{rr}}+2 \mathrm{k}_{\mathrm{r} 1}-2\left(\mathrm{\Upsilon} / \mathrm{r}_{0}^{2}\right)\right] \\
\mathrm{C}_{44}=1 / 2 \mathrm{a}\left[(1 / 3) \mathrm{k}_{\mathrm{r}}-(1 / 6) \mathrm{k}_{\mathrm{rr}}+2 \mathrm{k}_{\mathrm{r} 1}+(2 / 3)\left(\mathrm{\Upsilon} / \mathrm{r}_{0}^{2}\right)-\mathrm{A}^{2} / \mathrm{B}\right]
\end{gathered}
$$

where $\mathrm{A}=-\left[(2 / 3) \mathrm{k}_{\mathrm{r}}-(1 / 3) \mathrm{k}_{\mathrm{rr}}-(8 / 3)\left(\Upsilon / \mathrm{r}_{0}^{2}\right)\right], \quad \mathrm{B}=\left[(4 / 3) \mathrm{k}_{\mathrm{r}}-(2 / 3) \mathrm{k}_{\mathrm{rr}}+(32 / 3)\left(\Upsilon / \mathrm{r}_{0}^{2}\right)\right]$

Solving the secular determinant along [100] direction one gets

(i) at zone centre $(\Gamma)$

(ii) at zone boundary $(\mathrm{X}$ )

$$
\left(\omega_{\mathrm{LO}}\right)^{2}(\Gamma)=2 / \mathrm{m}\left[(4 / 3) \mathrm{k}_{\mathrm{r}}-(2 / 3) \mathrm{k}_{\mathrm{rr}}+(32 / 3)\left(\Upsilon / \mathrm{r}_{0}^{2}\right)\right]
$$

$$
\begin{gathered}
\left(\omega_{\mathrm{LO}}\right)^{2}(\mathrm{X})=1 / \mathrm{m}\left[(4 / 3) \mathrm{k}_{\mathrm{r}}-(2 / 3) \mathrm{k}_{\mathrm{rr}}+8 \mathrm{k}_{\mathrm{r} 1}+(40 / 3)\left(\Upsilon / \mathrm{r}_{0}^{2}\right)\right](6) \\
\left(\omega_{\mathrm{TO}}\right)^{2}(\mathrm{X})=1 / \mathrm{m}\left[(4 / 3) \mathrm{k}_{\mathrm{r}}-(2 / 3) \mathrm{k}_{\mathrm{rr}}+4 \mathrm{k}_{\mathrm{r} 1}+(20 / 3)\left(\Upsilon / \mathrm{r}_{0}^{2}\right)+\left\{(4 / 3) \mathrm{k}_{\mathrm{r}}-(2 / 3) \mathrm{k}_{\mathrm{rr}}-(16 / 3)\left(\Upsilon / \mathrm{r}_{0}^{2}\right)\right\}\right]
\end{gathered}
$$

\section{Numerical Computation}

With the help of equations (5), (6) and (7) along with equilibrium condition of the lattice model parameters are evaluated.

Input data for evaluating model parameters $\mathrm{k}_{\mathrm{r}}, \mathrm{k}_{\mathrm{r} 1}, \mathrm{k}_{\mathrm{rr}}$ and $\left(\mathrm{r} / \mathrm{r}_{0}{ }^{2}\right)$ are given in table $1 \& 2$ while evaluated values of model parameters are given in table 3 .

Table-1:zone boundary phonon frequencies of $\mathrm{Si}$

\begin{tabular}{|c|c|c|c|c|}
\hline \multirow{2}{*}{ Crystal } & \multicolumn{3}{|c|}{$\begin{array}{c}\text { Zone boundary and zone centre } \\
\text { phonon frequencies }(\mathbf{1 0} \mathbf{1 2} \mathbf{H z})\end{array}$} & Reference \\
\hline \multirow{2}{*}{$\mathrm{Si}$} & $v_{\mathrm{LO}}(\mathrm{X})$ & $v_{\mathrm{TO}}(\mathrm{X})$ & $v_{\mathrm{LO}}(\Gamma)$ & Nilsson and Nelin \\
& 12.32 & 13.90 & 15.53 & {$[9]$} \\
\cline { 2 - 4 } & & & & \\
\end{tabular}

Table-2: Lattice constant and mass of Si

\begin{tabular}{|c|c|c|}
\hline Crystal & Lattice constant (2a) & Mass(m) \\
\hline $\mathrm{Si}$ & $5.4307 \times 10^{-8} \mathrm{~cm}$ & $46.629 \times 10^{-24} \mathrm{gm}$ \\
\hline
\end{tabular}

Table-3:Evaluated values of Model parameters of Si

\begin{tabular}{|c|c|c|c|c|}
\hline \multirow{2}{*}{ Crystal } & \multicolumn{2}{|c|}{ F orce Constants $\left(\mathbf{1 0}^{\mathbf{4}}{\left.\mathbf{d y n e ~} \mathbf{~ c m}^{-1}\right)}^{\mathbf{- 1}}\left(\Upsilon / \mathrm{r}_{0}{ }^{2}\right)\right.$} \\
\hline \multirow{2}{*}{$\mathrm{Si}$} & $\mathrm{k}_{\mathrm{r}}$ & $\mathrm{k}_{\mathrm{r} 1}$ & $\mathrm{k}_{\mathrm{rr}}$ & \\
\cline { 2 - 5 } & -2.141340 & 0.535335 & -28.824330 & 0.548956 \\
\hline
\end{tabular}

Using the evaluated values of model parameters elastic constants $\mathrm{C}_{11}, \mathrm{C}_{12}, \mathrm{C}_{44}$ and Bulk modulus are evaluated using equations (2),(3)\&(4). 
Table 4: Elastic cnstants and Bulk modulus in units of $10^{12}$ dyne $\mathrm{cm}^{-2}$

\begin{tabular}{|c|c|c|c|c|c|}
\hline & \multirow{2}{*}{$\begin{array}{c}\text { Experimental } \\
\text { values } \\
\text { Jakata and } \\
\text { Every } \\
\text { [6] }\end{array}$} & \multirow{2}{*}{$\begin{array}{c}\text { Present } \\
\text { Calculated } \\
\text { values }\end{array}$} & \multicolumn{3}{|c|}{ Calculated Values of others } \\
\hline & & & $\begin{array}{c}\text { Sokel and } \\
\text { Harrison [10] }\end{array}$ & $\begin{array}{l}\text { Chadi and } \\
\text { Martin [11] }\end{array}$ & $\begin{array}{c}\text { Baraff et al } \\
{[12]}\end{array}$ \\
\hline $\mathrm{C}_{11}$ & 1.775 & 1.552 & & & 1.207 \\
\hline $\mathrm{C}_{12}$ & 0.745 & 0.748 & & & 0.860 \\
\hline $\mathrm{C}_{44}$ & 0.807 & 0.789 & 0.717 & 0.943 & 0.317 \\
\hline $\begin{array}{l}\text { Bulk } \\
\text { Mod. }\end{array}$ & 1.088 & 2.000 & 2.00 & & \\
\hline
\end{tabular}

The calculated values of model parameters are used to obtain phonon dispersion curves of Si along [100],[11 0] and [111] directions.

Lattice specific heats at different temperatures is

$$
C_{v}=\frac{3 R}{6000} \sum_{v} g(v) E\left(\frac{h v}{k_{B} T}\right)
$$

$E_{x}=\frac{x^{2} e^{x}}{\left(e^{x}-1\right)^{2}}$ where $\mathrm{x}=\mathrm{hv} / \mathrm{k}_{\mathrm{B}} \mathrm{T} . \mathrm{h}=$ Plank's constant, $\mathrm{v}=$ frequency, $\mathrm{k}_{\mathrm{B}}$ is Botzmann Constant, $\mathrm{T}=$ temperature of crystal, $\mathrm{R}=$ Universal gas constant.

The computed values of $\mathrm{C}_{\mathrm{v}}$ are used to find Debye characteristic temperatures from standard table of $\left(\mathrm{C}_{\mathrm{v}}\right.$ - $\theta_{\mathrm{D}} / \mathrm{T}$ ) from Saha and Srivastava [13].

\section{Results and Discussion}

\section{Elastic Constants}

The calculated values of elastic constants $\mathrm{C}_{11}, \mathrm{C}_{12}$ and $\mathrm{C}_{44}$ and Bulk modulus of $\mathrm{Si}$ in the present work along with their experimental values and calculated values of by other workers are shown in the Table 4 for comparison.

Calculated result of $\mathrm{C}_{44}$ differs slightly with the experimental value but superior to the calculated value of Baraff et al [12]. Calculated values for $\mathrm{C}_{11}$ and $\mathrm{C}_{12}$ are in satisfactory agreement with their experimental results. The bulk modulus calculated in the present work is found to be nearly twice the experimental value. Surprisingly the calculated value of bulk modulus is almost equal to the value obtained by Harrison and Sokel [14] calculated on the basis of linear combination of atomic orbitals (LCAO).

\section{Phonon frequencies}

Propagation of acoustic phonons in Si on the basis of two lattice dynamical models: a bond-charge model and effective force constant model consisting of only short range forces have been investigated by Tamura et al. [15]. Mazur and Pollman [16] investigated lattice dynamics of Si with semi empirical approach using tight binding green functions and dynamical matrix of the system has been set up. Elastic constants and normal mode frequencies of Si has been computed with empirical Many-Body potentials 
and compared with experimental results by Cowley [17]. None of the models tested is completely satisfactory.

The results of phonon dispersion curves in present work are shown in Fig.1. along three symmetry directions [100], [110] and [111].The agreement of the results with the experimental values of Dolling [18] and Nilsson and Nelin [9] shown in the figures is fairly satisfactory. Our results are comparable with those of Tubino et al. [19] and superior over the results of Martin [20], Soma and Marita [21] and Sinha et al. [22].

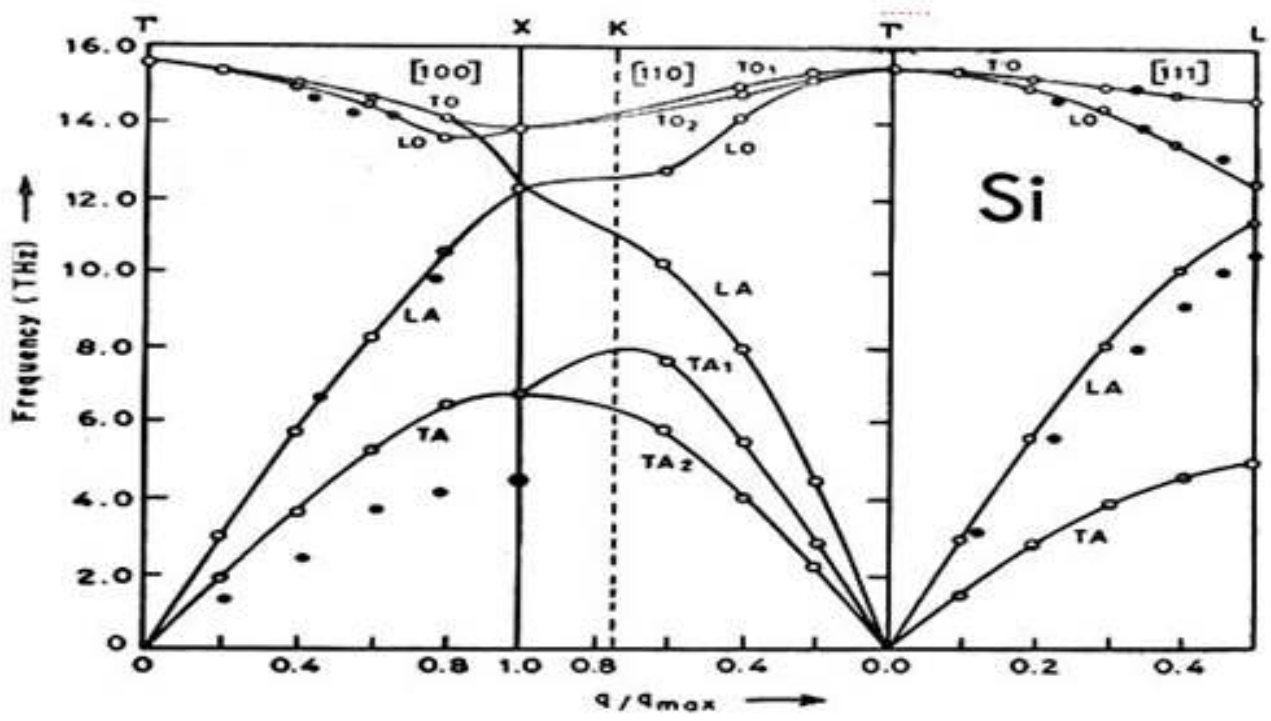

Fig.1: Phonon dispersion curves of Si along symmetry direction [100],[110] and [111]. Solid circles (•) represent the experimental results due to Dolling [18], Nilsson and Nelin [9]. Solid lines represent calculated curve.

\section{Debye temperature}

Calculated Debye temperatures of Si are plotted against temperature in Fig.5 along with experimental points of Flubacher and Leadbetter [23] giving fairly satisfactory agreement. The calculated values deviate from experimental values at higher temperature. Divergence of the calculated result with experimental results is almost same as that of 16 parameter BVK model of Zdetsis and Wang (1979). Thus only four parameter present harmonic model provides satisfactory result of Debye temperature.

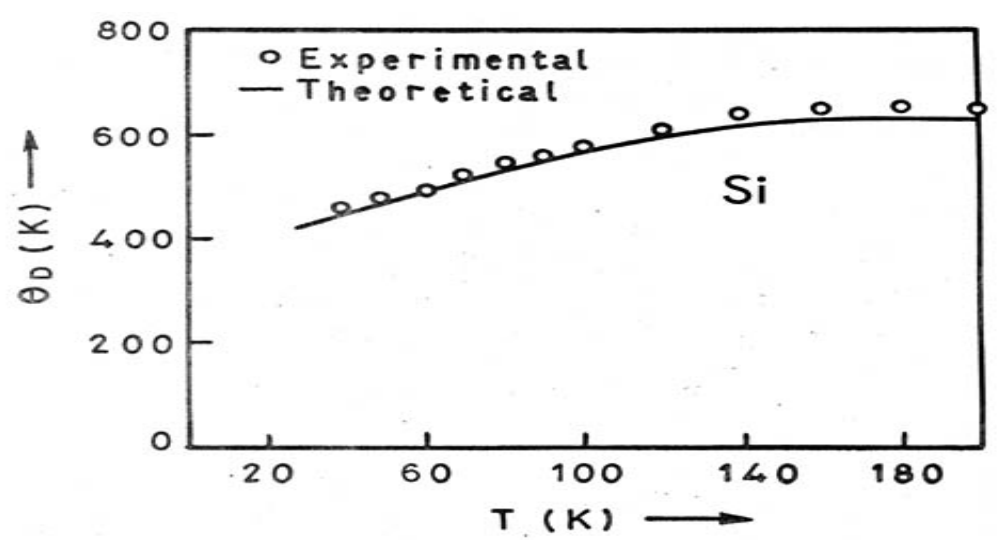

Fig.2: ( $\left.\theta_{D}-T\right)$ curve for Si. Experimental points (0) are due to Flubacher and Leadbetter [23]. 
S.R.B. Thapa / BIBECHANA 9 (2013) 13-17 : BMHSS, p.17 (Online Publication: Nov., 2012)

\section{Conclusion}

The present lattice dynamical model having four disposable parameters which is successful in explaining the phonon dispersion relations, elastic constants and Debye temperature of diamond, when extended for another diamond structure crystal $\mathrm{Si}$ is capable to explain its lattice dynamic properties- phonon frequencies, elastic constants and Debye temperature. This model which does not require the employment of elastic constants for the evaluation of its model parameters very satisfactorily reproduces the values of elastic constants and bulk modulus of $\mathrm{Si}$. The results for these quantities obtained on theoretical considerations based on pseudopotential and LCAO theories are found not superior and in some cases far inferior to the present results. This gives an emphasis on the suitability of the application of valence force fields to the covalent crystals which gave highly directional bonds resulting from the well defined orbital hybridization. Introduction of interaction terms for changes in bond length and bond angles in the present formulation may improve the features of the present results.

\section{References}

[1] M.T. Yin and Marvin L. Cohen, Phys. Rev.B,26 (1982) 3259.

[2] A. Fleszar and R. Resta, Phys. Rev.B, 34 (1986) 7140.

[3] G. Bose, B.B.Tripathi and H.C. Gupta, J. Phys. Chem. Solids, 34 (1973) 1867.

[4] A. D. Zdetsis and C. S. Wang, Phys. Rev.B, 19 (1979) 2999.

[5] H. Zhao and J. B. Freund, J. Appl. Phys. 97 (2005) 024903.

[6] K. Jakata and A.G. Every, Phys. Rev.B, 77 (2008) 174301.

[7] R. Maranganti and P. Sharma, Phys. Rev. Letters ,98 (2007) 195504.

[8] S. R. B. Thapa J. Purvanchal Acad. Sc.,17 (2011) (accepted paper).

[9] G. Nilsson and G. Nelin, Phys. Rev.B, 6 (1972) 3777.

[10] R. Sokel and W.A. Harrison, Phys. Rev. Letters, 36 (1976) 212.

[11] D.J. Chadi and R. M. Martin, Solid State Commun.,19 (1976) 193.

[12] G.A. Baraff, E.O. Kane and M. Schuluter, Phys. Rev.B, 21 (1980) 5662.

[13] M. N. Saha and B. N. Srivastava, A Treatise on Heat, $5^{\text {th }}$ ed., Indian Press, Alllahabad (1965).

[14] W.A. Harrison and R. Sokel, J.Chem. Phys.,65 (1976) 379.

[15] S. Tamura, J.A. Shields and J.P. Wolfe, Phys. Rev.B ,44 (1991) 3011.

[16] A. Mazur and J. Pollman, Phys. Rev.B, 39 (1989) 5261.

[17] E. Roger Cowley, Phys. Rev.Lett. ,60 (1988) 2379.

[18] G. Dolling, Inelastic scattering of neutrons, IAEA(Vienna) vol.II, (1965) p-249.

[19] R. Tubino, L. Poseri and C. Zebri, J. Chem. Phys.,56 (1972) 1022.

[20] R.M. Martin, Phys. Rev., 186 (1959) 871.

[21] T. Soma and A. Marita, J. Phys. Soc. Japan, 32 (1972) 38.

[22] S. K. Sinha R.P. Gupta and D.L. Price, Phys. Rev.B, 9 (1974 )2564.

[23] P. Flubacher and A.J. Leadbetter, Philos. Mag.,4 (1959) 273. 